Instruments and Methods

\title{
Glacier velocities from time-lapse photos: technique development and first results from the Extreme Ice Survey (EIS) in Greenland
}

\author{
Yushin AHN, ${ }^{1}$ Jason E. BOX ${ }^{1,2}$ \\ ${ }^{1}$ Byrd Polar Research Center, The Ohio State University, 1090 Carmack Road, Columbus, Ohio 43210-1002, USA \\ E-mail: ahn.74@osu.edu \\ ${ }^{2}$ Department of Geography, The Ohio State University, 1036 Derby Hall, 154 North Oval Mall, Columbus, \\ Ohio 43210-1361, USA
}

\begin{abstract}
Automated digital cameras were installed in May-June 2007 beside major West Greenland marine-terminating glaciers as part of the Extreme Ice Survey (EIS). EIS cameras began imaging the lowest $4 \mathrm{~km}^{2}$ of the glacier at hourly intervals throughout sunlit periods of the year. This study presents the development of techniques for quantifying glacier velocity from a single camera perspective. A Multi-Image/Multi-Chip matching procedure yields higher matching skill than conventional matching, and facilitates false-match rejection via a clustering scheme. The matching of motionless on-land features facilitates compensating camera motion. Ray projection to a known terrain elevation allows the assigning of scale to convert pixel displacements to velocity units. With the 10.2-megapixel camera system, velocities on relatively fast glaciers can be resolved at distances up to $\sim 4 \mathrm{~km}$. At a distance of $2 \mathrm{~km}$, a demonstrated precision of $\sim 0.5$ pixels yields a $\sim 0.5 \mathrm{~m}$ footprint size. Daily velocities indicate progressive multi-day velocity accelerations associated with calving. Deceleration trends are associated with the regrowth of resistive stress after major calving. The higher observation frequency available to terrestrial photogrammetry indicates higher observed intra-seasonal velocity range than observable by the at-best weekly satellite snapshots.
\end{abstract}

\section{INTRODUCTION}

Greenland outlet glaciers have been delivering highly variable and increasing quantities of ice to the adjacent seas from the vast inland ice-sheet reservoir, leading to increased rates of global sea-level contribution. This insight is due largely to satellite remote sensing that has revealed glacier surface velocity (e.g. Joughin and others, 2004; Luckman and others, 2006), calving-front position (e.g. Sohn and others, 1998; Csatho and others, 2008), thinning/ thickening rates (e.g. Howat and others, 2007) and ice discharge (Rignot and Kanagaratnam, 2006). Aerial photography (Bauer, 1968; Carbonnell and Bauer, 1968; Fountain, 1983; Fastook and others, 1995; Motyka and others, 2008), terrestrial photogrammetry (Brecher and Thompson, 1993; Amundson and others, 2008) and repeated airborne laser altimeter surveys (Krabill and others, 2000; Abdalati and others, 2001) have also proven effective in quantifying glacier dynamics.

Analysis of glacier-change time series on annual to decadal scales has been conducted by, for example, Sohn and others (1998), Joughin and others (2004), Luckman and others (2006) and Csatho and others (2008). However, observing ice-dynamical quantities at a frequency shorter than $\sim 1$ week has remained at the technological frontier. Approaches employing in situ GPS (e.g. Hamilton, and Whillans, 2000), auto-theodolite reflectors (e.g. Harper and others, 2007), terrestrial laser scanning (Schwalbe and others, 2008) and radar interferometry (Chapuis and others, 2010) have begun to fill this observational gap.

Velocities determined from time-lapse photogrammetry have the advantage of providing high spatial and temporal resolution sampling. In situ GPS or theodolite reflectors, moving with the glacier, provide discrete velocity points along a trajectory in the Lagrangian frame. Time-lapse photogrammetry offers an alternative observational frame, enabling velocity to be derived through fixed locations in the Eulerian frame.

Time-lapse photogrammetry in glaciology is not new. Harrison and others (1992) described the difficulties of feature tracking in the calculation of absolute speed. Recent advances in commercially available digital camera technology, solid-state data storage and GPS have greatly facilitated terrestrial time-lapse photogrammetry. Evans (2000) summarized image-processing stages for motion tracking in sequential images by image-matching and -filtering techniques. Motyka and others (2003) and $\mathrm{O}^{\prime} \mathrm{Neel}$ and others (2003) used time-lapse photogrammetry to determine the horizontal terminus-area changes at LeConte Glacier, Alaska, USA. Applying photogrammetric techniques, Maas and others (2006) and Dietrich and others (2007) observed ice velocity and tidal effects on the lower reach of Jakobshavn Isbræ, West Greenland.

This study focuses on the development of techniques for calculating ice displacement and velocity variability from single monoscopic camera stations installed on land beside glacier termini in West Greenland. We first discuss the various problems encountered. We then present techniques for image stabilization. Next, solutions in image-feature matching, displacement calculation and the conversion of image-space displacements to metric velocity are described. Error budgets and temporal/spatial resolution analyses are made. Finally, glacier dynamics insights are provided, with a more comprehensive application of this technique in glacier-climate sensitivity studies deferred to 

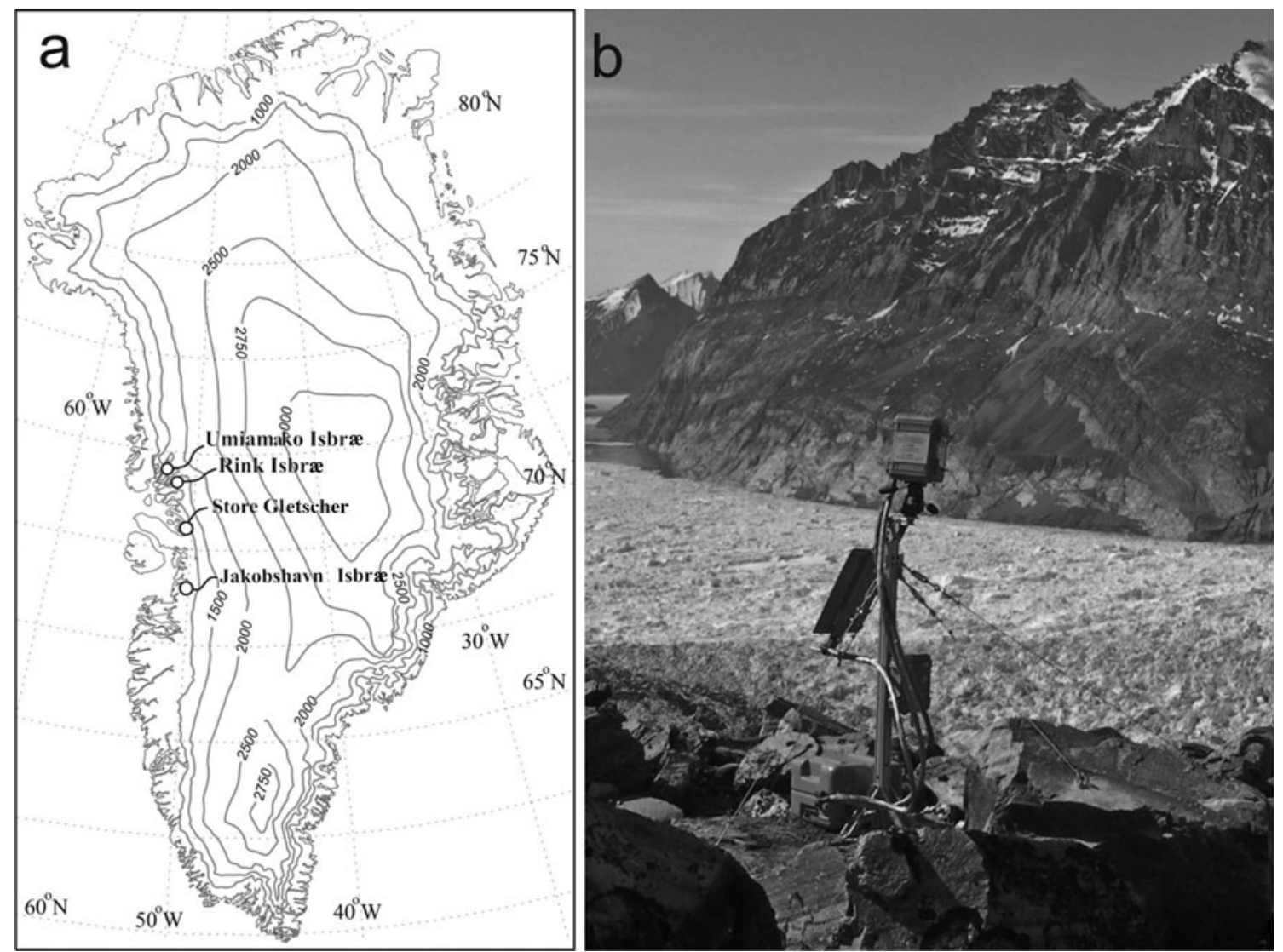

Fig. 1. (a) Time-lapse camera locations; (b) station set-up at Umiamako B.

future work. This work is to serve as the methodological foundation for subsequent quantitative work of the Extreme Ice Survey (EIS).

Table 1. EIS time-lapse station hardware specification

\begin{tabular}{|c|c|}
\hline Camera & Nikon D200 \\
\hline Lens & Nikkor 20, 24, $28 \mathrm{~mm}$ \\
\hline Image format & $3872 \times 2592$ pixels, 10.2 megapixels \\
\hline Timer & $\begin{array}{l}\text { Custom-designed by N. Humphrey; later replaced } \\
\text { with custom timer developed by US National } \\
\text { Geographic Society's Remote Imaging Laboratory }\end{array}$ \\
\hline Enclosure & $\begin{array}{l}\text { Pelican case with optically neutral plastic window } \\
\text { custom-installed }\end{array}$ \\
\hline Power & 50 Ah gel cell battery, $10 \mathrm{~W}$ solar panel \\
\hline Support & Steel cables, rock bolts \\
\hline
\end{tabular}

\section{TIME-LAPSE CAMERAS}

\subsection{Data}

Digital single-lens reflex cameras with fixed focal length lenses were installed on land beside the termini of marineterminating glaciers (Rink, Store, Umiamako and Jakobshavn glaciers) in West Greenland during May-June 2007 (Fig. 1; Table 1). Table 2 lists site information. For the sunlit period of the yeaar, photos were acquired each hour. The interval timer reduced the number of photos, depending on the time of year, such that during winter the image acquisition rate decreased to a minimum of one or two frames per day.

\subsection{Problems encountered}

The effects of falling snowflakes and rain droplets, snow and rain on the ground, lens internal reflections and enclosure window optical distortion all contributed to variable amounts of image clarity. Clouds blocked some

Table 2. EIS time-lapse camera site information

\begin{tabular}{|c|c|c|c|c|c|}
\hline Site & Lat. & Long. & Data period (2007) & $\begin{array}{l}\text { Lens focal length } \\
\qquad \mathrm{mm}\end{array}$ & $\begin{array}{c}\text { Elevation } \\
\text { ma.s.l. }\end{array}$ \\
\hline Rink Isbræ & $71^{\circ} 42^{\prime} \mathrm{N}$ & $51^{\circ} 37^{\prime} \mathrm{W}$ & 11 June-25 September & 20 & 440 \\
\hline Store Gletscher A & $70^{\circ} 23^{\prime} \mathrm{N}$ & $50^{\circ} 39^{\prime} \mathrm{W}$ & 9 June-24 September & 24 & 327 \\
\hline Store Gletscher B & $70^{\circ} 24^{\prime} \mathrm{N}$ & $50^{\circ} 37^{\prime} \mathrm{W}$ & 15 June-24 September & 24 & 240 \\
\hline Umiamako A & $71^{\circ} 42^{\prime} \mathrm{N}$ & $52^{\circ} 23^{\prime} \mathrm{W}$ & 11 June-25 August & 20 & 629 \\
\hline Umiamako B & $70^{\circ} 43^{\prime} \mathrm{N}$ & $52^{\circ} 19^{\prime} \mathrm{W}$ & 11 June-26 September & 20 & 637 \\
\hline Jakobshavn Isbræ & $69^{\circ} 07^{\prime} \mathrm{N}$ & $49^{\circ} 43^{\prime} \mathrm{W}$ & 11 June-25 September & 28 & 132 \\
\hline
\end{tabular}




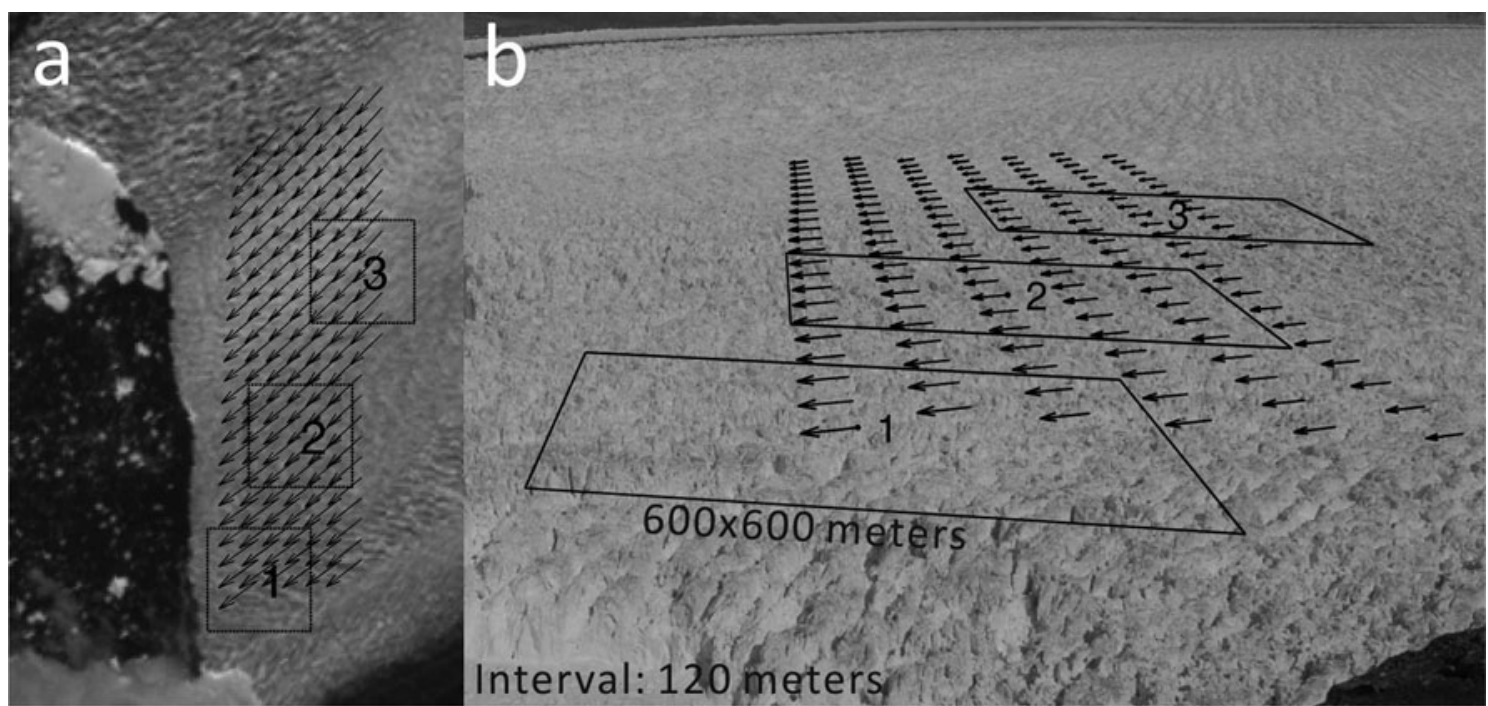

Fig. 2. The effects of perspective: (a) Landsat velocity determined from image pairs spanning 7-26 July 2002; (b) time-lapse photogrammetry derived velocities for the interval 22-23 July 2007. Arrows are (a) velocity and (b) pixels $\mathrm{d}^{-1}$ image displacements.

glacier observations, leading to an image loss rate of 8 $12 \%$ (Table 3). West Greenland fjord cloudiness is minimized in the lower atmosphere by the force and dryness of katabatic winds.

Pixels affected by extremes in illumination, i.e. under- and overexposure, are not always completely compensated by automatic camera exposure. The shadows and 'hot spots' lack brightness variation and these can confound feature identification. Camera malfunctions have occurred due to excessive vibration presumably caused by winds. Temporary sticking of the camera shutter has occurred at $<-30^{\circ} \mathrm{C}$. The camera timer has failed in more than one instance, leading to data gaps of more than 10 days. Wild animals have scratched enclosure windows and elsewhere have left tooth-marks. Thick plastic conduit successfully protects power cables. Manual image inspection is performed to remove images rendered useless by these problems. The above problems account for a loss rate of $6-10 \%$ (Table 3 ). Including image loss owing to fog, the total loss rate is $15-20 \%$.

\subsection{Spatial resolution}

Image spatial resolution varies across the glacier scene, especially given the oblique $75-85^{\circ}$-from-vertical view of these installations. We simulate the spatial resolution pattern by assuming a horizontal plane. The pixel ground coverage (Fig. 2) is $0.62,0.93$ and $1.24 \mathrm{~m}$ with distances 2,3 and $4 \mathrm{~km}$, respectively, from $20 \mathrm{~mm}$ nominal focal length and a $6.2 \mu \mathrm{m}$ camera detector array element size. Because of the oblique view, what would be squares in satellite imagery are trapeziums (Fig. 2). Displacement magnitudes must increase to remain resolvable as distance from the camera increases.

\subsection{Landsat imagery}

Glacier surface velocities calculated using the offset of visible surface features between repeat, co-registered Enhanced Thematic Mapper Plus (ETM+) images (Ahn and Howat, 2009; Howat and others, 2010) are available to this study. We use four image pairs for Rink Isbræ, one pair for Store Gletscher, five pairs for Umiamako and five pairs for Jakobshavn Isbræ.

\section{PHOTOGRAMMETRIC METHODS AND RESULTS}

\subsection{Area-based image matching}

Image area-based 'correlation matching' is implemented to identify feature motion between successive images. Glacier motion is evident as image pixel column and row offsets, referred to here as 'displacements'. We use only the midday photos to provide the most continuous coverage of the year and with the highest sun illumination angles.

Square image subsets or 'chips' or 'windows' are extracted from a 'reference image' and a 'search image'. A reference chip is coordinated within a search chip larger than the reference chip. As the reference chip is nudged in the image column and row directions within the search chip, a correlation coefficient is calculated from all the combinations of reference chip placement, producing a correlation grid. The maximum in the correlation map corresponds with a 'conjugate point' that is assumed to be the same point in the reference and search images. The pixel offset in the image column and row direction thus yields the feature displacement. A quadratic surface fitting around the correlation peak is performed to obtain sub-pixel precision. Further details of this technique are provided by Schenk (1999), and for a glaciological application see Scambos and others (1992).

Table 3. Daily image loss rates (\%)

\begin{tabular}{lccc}
\hline Site & $\begin{array}{c}\text { Loss rate from } \\
\text { clouds }\end{array}$ & $\begin{array}{c}\text { Loss rate from } \\
\text { other factors }\end{array}$ & Total \\
\hline Rink Isbrae & 9.5 & 5.9 & 15.4 \\
Store Gletscher A & 11.5 & 5.8 & 17.3 \\
Store Gletscher B & 7.8 & 6.8 & 14.6 \\
Umiamako A & 9.9 & 9.8 & 19.7 \\
Umiamako B & 11.2 & 7.4 & 18.6 \\
Jakobshavn Isbræ & 11.2 & 4.1 & 15.3 \\
& & & \\
\hline
\end{tabular}




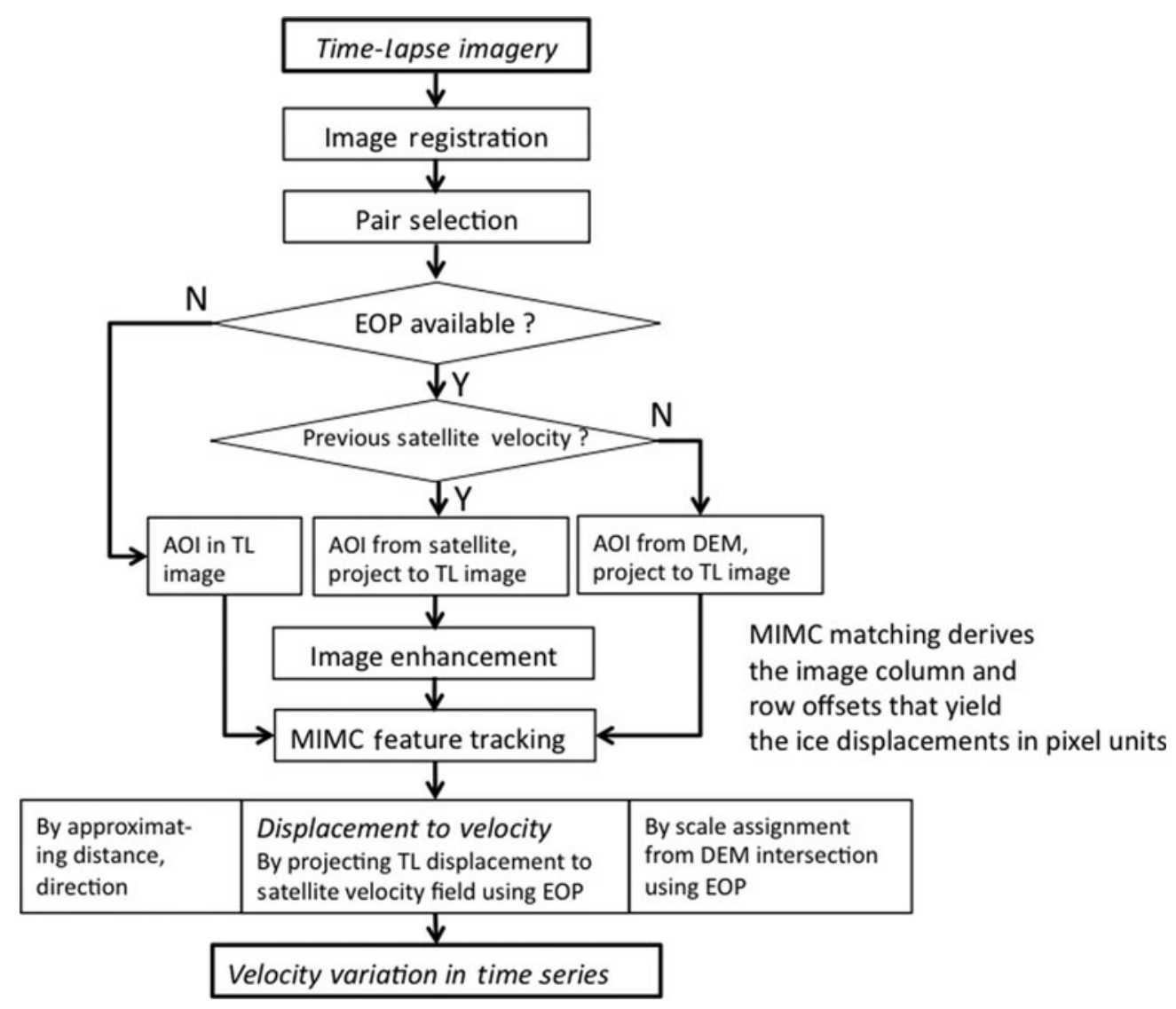

Fig. 3. The work flow of mono time-lapse camera processing to derive glacier velocity. AOI: area of interest; TL: time lapse; EOP: exterior orientation parameter.

\subsection{Registration}

Camera motion caused by wind gusts, camera platform settling and other factors (e.g. thermal expansion/contraction of the camera platform) introduces rotation and image column and row shifts between image pairs spanning time. Image registration compensates for camera motion, aligning images so that image comparison through time can accurately and precisely represent glacier displacements. Registration is a first processing step (flow chart, Fig. 3) and involves matching techniques described later. We refer to motion-compensated images as having been 'registered' (Image registration in flow chart, Fig. 3). In extreme cameramotion compensation, registration offsets are up to 38 pixels. Typical offsets are, however, in the $0-8$ pixel range (Table 4). Nonzero average rectification offsets indicate camera 'exterior orientation' drift.

Table 4. Pixel offset statistics from camera motion compensation

\begin{tabular}{lccc}
\hline Site & Average & Std dev. & Max. \\
\hline Rink Isbræ & 1.9 & 1.1 & 8.1 \\
Store Gletscher A & 8.5 & 8.1 & 37.9 \\
Store Gletscher B & 2.0 & 1.8 & 11.6 \\
Umiamako A & 2.9 & 4.3 & 19.4 \\
Umiamako B & 3.1 & 2.4 & 9.6 \\
Jakobshavn Isbræ & 2.3 & 1.3 & 7.0 \\
\hline
\end{tabular}

An approach for compensating camera motion involves a registration technique that transforms one image to an equivalent perspective in the other, i.e. from a chosen source image to a destination image (Brown, 1992). Registration, as such, requires conjugate points on stationary features, in our case, sharp rock edges and crack features. Feature identification is problematic when the land-surface properties change over time owing to changing surface wetness reflectivity, snow-cover accumulation/ ablation, permafrost creep and vegetation. Whether the solar illumination is direct or diffuse, i.e. causes shadows or not, is important. Direct beam illumination introduces a time-varying orientation and length of shadows. Diffuse illumination is preferred, as it illuminates what would otherwise be obscured by shadows. Direct illumination in one image and diffuse illumination in another creates an undesirable image pair.

We solve the registration problem by choosing a distribution of control points (CPs) on land both on the near and far sides of the glacier. A sample of 25 neighboring points around each CP is generated. The correlation-matching procedures then identify conjugate points. The maximum correlation point among the $25 \mathrm{CP}$ neighbor points is chosen for the registration via a transformation model. When foreground and 'farground' CPs are available, as in the case of the Rink, Umiamako and Store glacier sites, a 'projective' transformation model (Slama and others, 1980; Zitová and Flusser, 2003) is used. A simpler linear conformal transformation model (Slama and others, 1980) is used for the Jakobshavn Isbræ site, where only foreground CPs are available. 
For projective transformation, the outlier-insensitive random sample consensus (RanSaC) correlation procedure (Fischler and Bolles, 1981) is applied. The image is divided into quadrants, with CPs selected from each quadrant. Then all possible combinations of sampling with at least $1 \mathrm{CP}$ from each quadrant are used to ensure a wide distribution of CPs and thus a more reliable transformation solution.

\subsection{Multi-Image/Multi-Chip (MIMC) matching}

We use 'area-based' image matching to (1) compensate camera motion by identifying motionless features on land and (2) determine ice displacements from multiple images spanning time. We use a set of 15 image pairs to obtain robust matching solutions. Here we discuss this MIMC approach (MIMC feature tracking in flow chart, Fig. 3).

The first MIMC procedure involves multiple chip sizes. Optimal chip size varies with feature displacement rate, viewing geometry, illumination, etc., and is determined empirically by balancing the requirements of feature uniqueness and the geometric distortion that grows with chip size. We use square chips of 30, 40 and 50 pixels on a side. The use of multiple chip sizes increases the matching success rate by enabling disqualification of infrequently occurring spurious correlation maxima, i.e. occurring only once among a larger set of valid results.

The second MIMC procedure is the use of multiple images (Image enhancement in flow chart, Fig. 3). In this case, before the image-matching procedures are followed, image enhancements are applied. First, a principal-component intensity image is extracted from the red, green and blue (RGB) bands (Gonzales and Woods, 2002). Then a $0^{\circ}$ and $90^{\circ}$ directional edge enhancement applied to the intensity image produces two more images. The $0^{\circ}$ and $90^{\circ}$ enhanced images are high-pass filtered using a $3 \times 3$ kernel $(-1-1-1 ;-18-1 ;-1-1-1)$ to extract image information corresponding to sharp features such as rifts and crevasse edges. Ultimately, five enhanced images are generated from the original image (Fig. 4).

Given that we apply three search-chip sizes to five enhanced images, MIMC identifies up to 15 matches per chip, in 30 images. Among these, the displacement results vary. Furthermore, the highest correlation is not always the most accurate solution. To identify the most accurate solution, a filtering scheme identifies a cluster of displacement results using a drop-in-the-bucket 'voting cell', also akin to a cluster. The displacement within the cell with the maximum count is chosen as the most accurate matching result. The width of the voting cell is 2 pixels, and the dimension of the region where voting cells are counted is defined by the spatial range of the 15 resultant displacement vectors. Another set of voting cells with a 1-pixel shift in image column and row directions is sampled to prevent a cluster from being divided at a cell boundary. See MIMC application to satellite imagery (Ahn and Howat, 2009).

\subsection{MIMC versus conventional matching}

Conventional correlation matching results for three bands (RGB) and three chip sizes $(30 \times 30,40 \times 40$ and $50 \times 50)$ are compared with MIMC results at image 'posts' having a 50-pixel image interval (Fig. 5). The conventional correlation result is illustrated for the red band with a $30 \times 30$ reference chip size in Figure $5 \mathrm{a}$ and b. MIMC results are displayed in Figure $5 c$ and $d$. We find that without any filtering (e.g. using a correlation threshold), MIMC results in fewer outliers than conventional matching. Enlarged Figure $5 b$ and d show how erroneous displacements are excluded in the MIMC cluster filtering. It is impossible to exclude spurious vectors in conventional matching when only one displacement vector is determined.

Using MIMC, we can also identify what type of image enhancement - i.e. intensity, edge, high-pass filtered and what chip size (30, 40 and 50 pixels on a side) - contributes most successfully (highest correlations) to the final displacement results. Intensity image pairs in all chip sizes consistently result in the highest correlations and therefore the highest contribution to the chosen displacement (Table 5). Edge and high-pass filtered image pairs contribute only 2$5 \%$ to the selected displacement retrievals. The directional or high-pass filtered images seem to outperform the principal-component images in hazy cases.

We applied additional filtering to MIMC results to eliminate outliers not removed by the voting cell approach, that is, (1) an empirically determined maximum possible displacement threshold of 40 pixels $^{-1}$, and (2) only accepting displacements that satisfy $\left(D_{i}-D_{\text {mean }}\right)<D_{\text {std }}$, where $D_{i}$ is the $i$ th displacement and $D_{\text {mean }}$ and $D_{\text {std }}$ are respectively the mean and standard deviation of a $5 \times 5$ window from a 'displacement grid' centered at the ith point. The displacement grid refers to the $50 \times 50$ pixel grid of posts (Fig. 5).

To verify the robustness of MIMC results, we first compare the MIMC principal-component intensity-image correlation values with that from conventional matching of RGB intensity images for the three chip sizes. Table 6 lists the proportion of posts where the correlation is higher for our approach compared with conventional matching. A correlation ratio of 0.5 indicates no improvement. When matching using principal-component intensity-image pairs, we find an average increase in correlation ratio of 0.25 more than conventional matching. Second, we compare the displacements between the nine conventional matching results and the MIMC filtered results. When the difference in image row and column displacement exceeds 2 pixels, we categorize the conventional matching results as 'fail' (Table 6). The failure rate is $3 \%$ or smaller.

There may be some consistency among the matching results on an image band basis. For example, red outperforms the other bands at Umiamako. The blue band performs best at Rink and Store glaciers (Table 6). A more comprehensive study of performance by bands may yield conclusive color-based matching improvements.

\subsection{Daily displacement calculations}

Once all images are co-registered, the matching procedures are applied to the ice-covered image areas in rectified images spanning 1-4 days. The image area that provides optimum results is usually near the glacier terminus, where the largest displacements are and distance to the camera is lowest. Pixel assortments nearer the camera contain more distinct feature information, i.e. better resolution. To develop a time series of glacier motion, we keep the target always on ice by choosing an image position represented by a relatively small $(20 \times 20$ pixel) area close to the terminus yet far enough upstream that any front retreat does not leave the target off the glacier.

Daily displacement calculations are based on photos selected from within 3 hours of the same hour of day to minimize uncertainty caused by changing illumination (Pair 


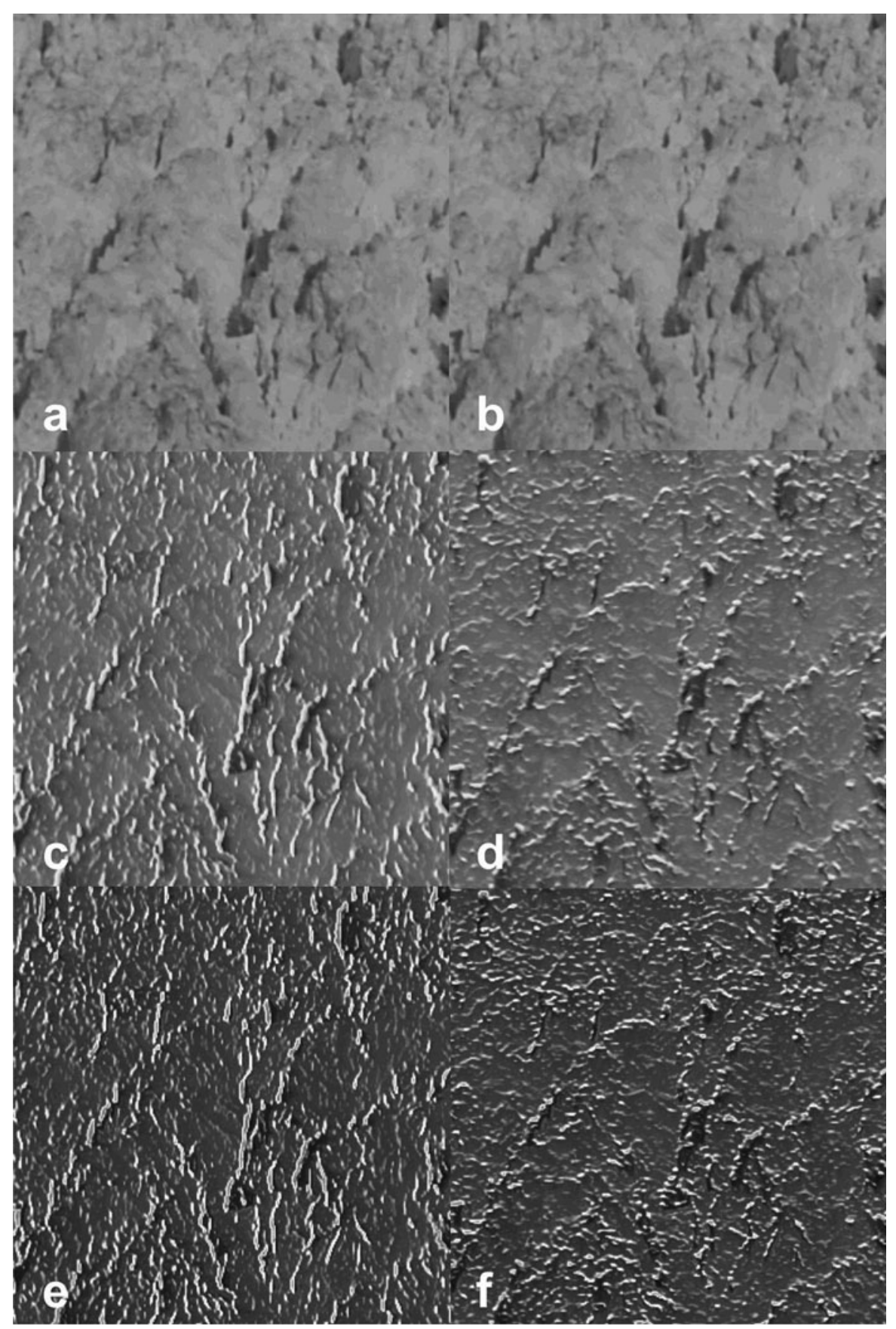

Fig. 4. (a) Original image, (b) intensity image and (c) $0^{\circ}$ edge-enhanced, (d) $90^{\circ}$ edge-enhanced, (e) $0^{\circ}$ edge + high-frequency enhanced and (f) $90^{\circ}$ edge + high-frequency enhanced images of a heavily crevassed portion of an image of Rink Isbræ.

Table 5. Contributions (\%) from different image types to final matching selections

\begin{tabular}{|c|c|c|c|c|}
\hline $\begin{array}{l}\text { Chip size } \\
\text { pixels }\end{array}$ & Image type & Rink Isbræ & Store Gletscher A & Umiamako A \\
\hline \multirow[t]{3}{*}{$30 \times 30$} & Intensity & 47.0 & 29.8 & 30.2 \\
\hline & Edge-enhanced & 2.1 & 5.4 & 2.7 \\
\hline & High-pass enhanced & 2.5 & 3.8 & 1.8 \\
\hline \multirow[t]{3}{*}{$40 \times 40$} & Intensity & 17.1 & 14.7 & 19.0 \\
\hline & Edge-enhanced & 2.8 & 4.2 & 2.9 \\
\hline & High-pass enhanced & 2.4 & 3.9 & 1.8 \\
\hline \multirow[t]{3}{*}{$50 \times 50$} & Intensity & 20.6 & 31.5 & 36.6 \\
\hline & Edge-enhanced & 2.7 & 3.4 & 2.5 \\
\hline & High-pass enhanced & 2.8 & 3.2 & 2.4 \\
\hline Total number of posts & & 1099 & 739 & 2703 \\
\hline
\end{tabular}




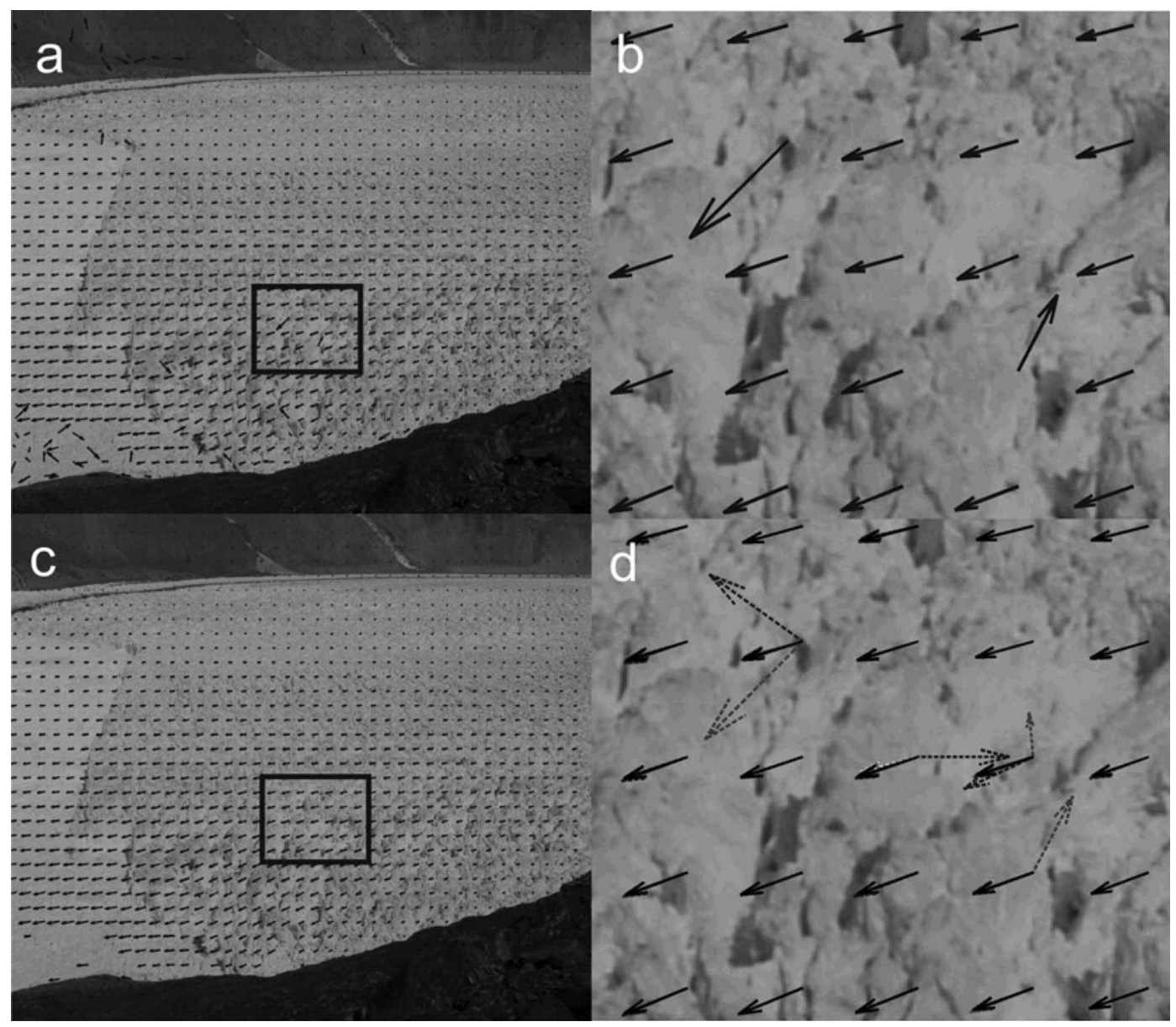

Fig. 5. Illustration of $30 \times 30$ reference chip red-band displacement results from conventional matching $(a, b)$ and from MIMC (c, d). Dashed arrows indicate outliers removed by the voting cell approach. Dashed arrows in (d) indicate cases where conventional matching fails.

selection in flow chart, Fig. 3). Changes that occur in images at times $t_{0}$ and $t_{1}$ are considered the average displacement at $\left(t_{0}+t_{1}\right) / 2$.

\subsection{Exterior orientation parameter (EOP) calculation}

EOPs describe the camera position in three-dimensional space, i.e. three $X, Y$ and $Z$ position coordinates and three rotation angles $\omega, \varphi$ and $\kappa$. As such, an object in three dimensions can be projected to image space, and the object in the image can also be projected to a surface or a plane (Slama and others, 1980) (EOP available in flow chart, Fig. 3).

The 'single photo resection' that calculates the EOPs requires more than three ground control points (GCPs) with known positions and corresponding image points. The GCPs are taken from Advanced Spaceborne Thermal Emission and

Table 6. Comparison between MIMC intensity and conventional matching

\begin{tabular}{|c|c|c|c|c|c|c|c|c|c|c|}
\hline \multirow{3}{*}{$\begin{array}{l}\text { Chip size } \\
\text { pixels }\end{array}$} & \multirow[t]{3}{*}{ Band } & \multicolumn{3}{|c|}{ Rink Isbræ } & \multicolumn{3}{|c|}{ Store Gletscher A } & \multicolumn{3}{|c|}{ Umiamako A } \\
\hline & & $N$ & Proportion & Fail & $N$ & Proportion & Fail & $N$ & Proportion & Fail \\
\hline & & & & $\%$ & & & $\%$ & & & $\%$ \\
\hline \multirow[t]{3}{*}{$30 \times 30$} & Red & 1059 & 0.74 & 3.1 & 710 & 0.69 & 3.7 & 2631 & 0.95 & 2 \\
\hline & Green & 1062 & 0.77 & 1.4 & 714 & 0.72 & 2.3 & 2649 & 0.78 & 1.4 \\
\hline & Blue & 1052 & 0.94 & 2.1 & 706 & 0.75 & 2.7 & 2632 & 0.88 & 1.3 \\
\hline \multirow[t]{3}{*}{$40 \times 40$} & Red & 1079 & 0.73 & 3.2 & 721 & 0.68 & 3.2 & 2651 & 0.97 & 1.5 \\
\hline & Green & 1082 & 0.80 & 1.0 & 723 & 0.72 & 2.0 & 2660 & 0.80 & 1.1 \\
\hline & Blue & 1077 & 0.94 & 2.2 & 717 & 0.74 & 2.7 & 2657 & 0.88 & 0.9 \\
\hline \multirow[t]{3}{*}{$50 \times 50$} & Red & 1073 & 0.70 & 3.3 & 716 & 0.69 & 3.4 & 2657 & 0.97 & 2 \\
\hline & Green & 1075 & 0.79 & 1.6 & 718 & 0.71 & 2.6 & 2665 & 0.81 & 1 \\
\hline & Blue & 1068 & 0.93 & 2.3 & 717 & 0.72 & 2.6 & 2661 & 0.87 & 1 \\
\hline $\begin{array}{l}\text { Total number } \\
\text { of posts }\end{array}$ & & 1099 & & & 739 & & & 2703 & & \\
\hline
\end{tabular}


Table 7. Registration error statistics

\begin{tabular}{lccc}
\hline Site & Average RMSE & $\begin{array}{c}\text { Std dev. } \\
\text { of RMSE } \\
\text { pixels }\end{array}$ & $\begin{array}{c}\text { Displacement } \\
\text { uncertainty } \\
\text { pixels }\end{array}$ \\
\hline Rink Isbræ & 0.26 & 0.09 & 0.52 \\
Store Gletscher A & 0.23 & 0.08 & 0.46 \\
Store Gletscher B & 0.25 & 0.08 & 0.47 \\
Umiamako A & 0.20 & 0.09 & 0.45 \\
Umiamako B & 0.26 & 0.07 & 0.49 \\
Jakobshavn Isbræ & 0.30 & 0.26 & 1.04 \\
\hline
\end{tabular}

Reflection Radiometer (ASTER) imagery and an ASTERderived digital elevation model (DEM).

The single photo resection is possible because the camera position is known by GPS and by identifying the conjugate features (e.g. mountain tops and valley intersections) in time-lapse images and in the ASTER image draped over the ASTER terrain model. We calculate that the uncertainties of ASTER imagery and elevation data are sources of error resulting in angular uncertainty of $\pm 0.3^{\circ}$, corresponding to a $\pm 30 \mathrm{~m}$ error at a $3 \mathrm{~km}$ distance, assuming the GPS position is error-free. The image space and ground space can be linked so that points in image space can be transferred to the ground space. We choose points in ground space and transfer them to the camera image space so that point intervals have a regular $120 \mathrm{~m}$ ground spacing (Fig. 2).

\subsection{Image-space displacement conversion to velocity}

We develop two approaches for converting pixel displacement to velocity (Displacement to velocity in flow chart, Fig. 3). The first is to calculate the 'scale factor'. In this case, the scale factor is a function of ground footprint size and iceflow direction. The footprint size increases with distance to the target, and changes with the changing position of displacements. In the case of the $20 \mathrm{~mm}$ focal length lens, we calculate a footprint size per pixel of $6.2 \mathrm{~m}$ at $1 \mathrm{~km}$ distance at the image center. The footprint size increases to $9.4 \mathrm{~m}$ at the image edges for the same distance. The distance between the camera station and the glacier can be approximated using satellite imagery. Because the EOPs and a DEM are available, we calculate the 3-D position where a ray from the camera intersects the DEM surface. First, the ray from the camera intersects an initial height, $h_{0}$, where the surface height, $h_{1}$, is then calculated. If $\left(h_{1}-h_{0}\right)$ is greater than a threshold of $5 \mathrm{~m}$, then the first surface height becomes the initial height for iteration, which stops when $\mathrm{d} h$ is $5 \mathrm{~m}$ or less. If the procedure does not converge after 50 iterations, the average height of the surface from the digital terrain model is assumed. The effect of a $\pm 15 \mathrm{~m}$ ASTER DEM uncertainty on scale assignment is $5 \%$ of the scale factor, if the usual target is $2 \mathrm{~km}$ away and the camera elevation is $300 \mathrm{~m}$ above the DEM.

The flow direction 'into' the frame partially compensates a 'foreshortening' effect that results in shorter than actual displacement when the camera captures motions that are not parallel to the camera plane. If the camera is installed perpendicular to the flow direction, as in the case of Store B and Umiamako B, this effect is less noticeable.
Another approach to assign scale is to carry out the projection of pixel displacements to the orthographic satellite-derived velocity plane. With the availability of Landsat-derived velocities and EOPs, we set a vertical plane that contains each Landsat velocity vector. Projecting timelapse displacements to the vertical plane enables comparison of velocities at equivalent posts, shown later.

\subsection{Error budget}

The two major sources of uncertainty in displacement calculations stem from image matching and projective transformation model-fitting errors. Dietrich and others (2007) analyzed the uncertainty in matching based on the steepness of parabola fitting in correlation, and concluded that the uncertainty is $<0.1$ pixel for a foreground reference target and $0.1-0.3$ pixels for the glacier feature. Skvarca and others (2003) more conservatively estimated a 0.5-pixel uncertainty for correlation matching and a 1.5-pixel uncertainty in registration. We compute a $0.23 \pm 0.08$ average registration root-mean-square error (RMSE) from projective transformation (Table 7). Since our area of interest is located between registration control points, the uncertainty in registration procedure can be estimated to be less. Correlation-matching uncertainty is difficult to quantify, since quadratic surface fitting uses a correlation value around a $3 \times 3$ or $5 \times 5$ pixel peak. Here a 0.3 -pixel uncertainty for matching can be considered conservative. When uncertainties are square-summed for each step, the daily displacement uncertainties for our sites (Table 7) are $0.52,0.46,0.47,0.45,0.49$ and 1.04 pixels, corresponding to 'on the ground' velocity uncertainties of $0.18 \mathrm{~m} \mathrm{~d}^{-1}$ at $1000 \mathrm{~m}$ distance at the image center and with ice motion perpendicular to the camera.

\subsection{Spatial and temporal resolution}

The minimum resolvable displacement and its related time interval are functions of camera focal length, pixel size projected onto the ground, target distance, ice velocity and registration precision. A first necessary condition for motion to be resolved is that the displacement exceed the registration and matching uncertainty of 0.3 pixels. In our case, the registration error is roughly twice the matching error.

Pixel footprint size, derived from the target distance, ice velocity and time-lapse interval are related parameters. For relatively slow glaciers, a longer time interval or closer features have a similar effect. The resolvable lapsing time, given displacement $\Delta p$ (pixel units), time interval $\Delta d$ (days), pixel footprint $F$ (length units), the uncertainty $\epsilon$ (pixels) and the error budget $\epsilon_{\mathrm{b}}$ expressed as a percentage, is $\Delta d=(\epsilon /(\Delta p \epsilon b)) \times 100 \%$. In the case of Rink Isbræ, which

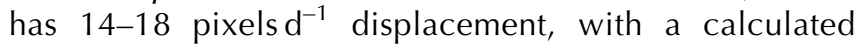
absolute uncertainty of 0.52 pixels, the displacement uncertainty is $20 \%$. The resolvable lapsing interval is thus $\sim 4.5$ hours. Halving the distance doubles $\Delta p$ and thus halves the minimum time interval of resolvable displacement to $\sim 2.5$ hours. A relatively slow glacier, flowing $2 \mathrm{~m} \mathrm{~d}^{-1}$, having 3.2-pixel displacement at a distance of $1000 \mathrm{~m}$, with $0.62 \mathrm{~m}$ pixel size, requires $>1$ day for a displacement to exceed the uncertainty. The distance to target and the glacier speed have a similar effect on resolution.

The temporal resolution depends on how the image pairs are selected. Pairs for sub-daily displacement are applicable by searching before and after the specific hour. Even hourly intervals (4hours, 6 hours, ... 24 hours) produce 


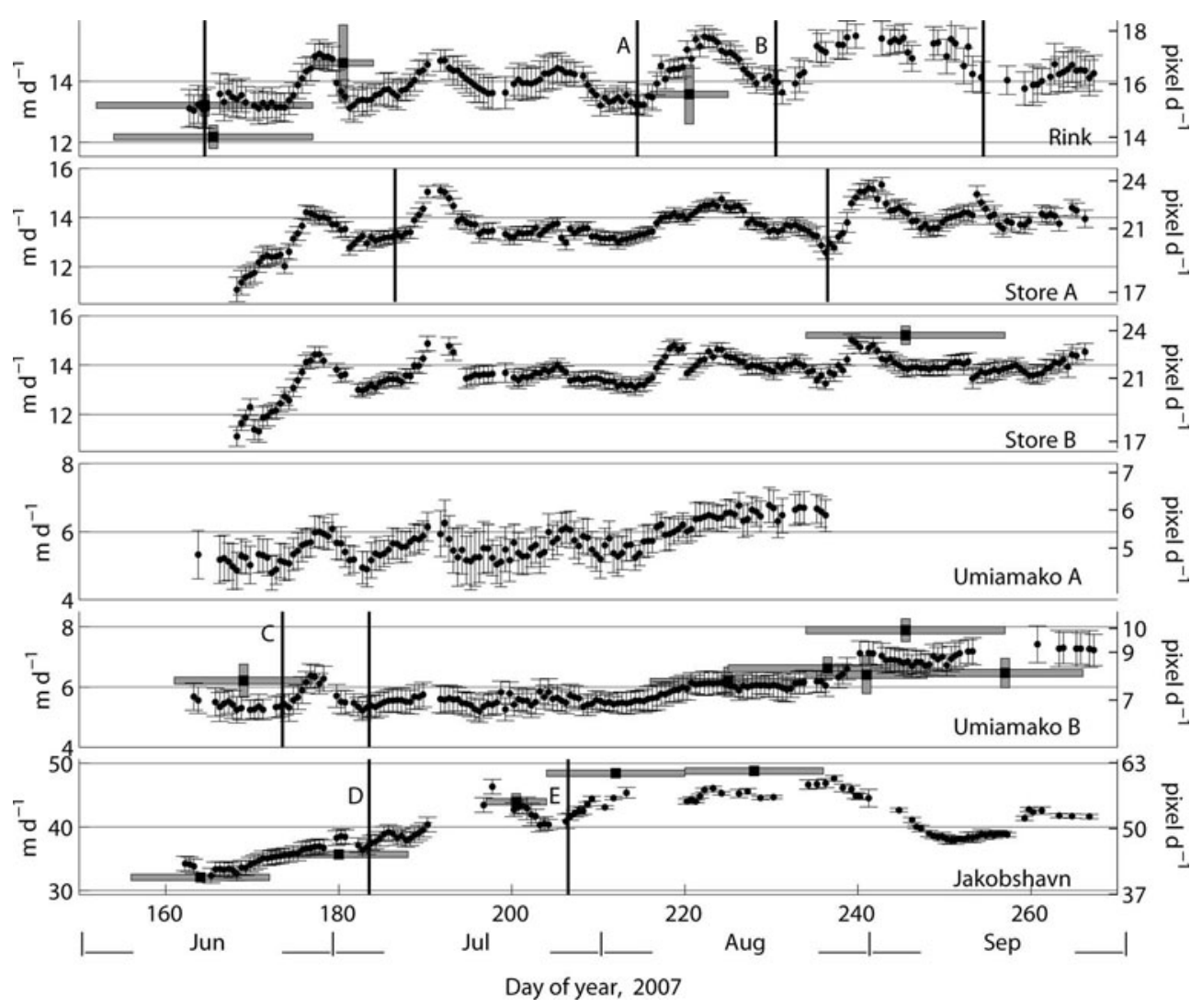

Fig. 6. Daily velocity variability at a point near the front of, respectively, Rink Isbræ, Store Gletscher A, Store Gletscher B, Umiamako A, Umiamako B and Jakobshavn Isbræ. Vertical lines indicate major calving events.

displacement results with even (integer) time coordinates. Combining with odd hour intervals ( 5 hours, 7 hours, ... 23 hours) can yield effective sub-hourly resolution.

\subsection{Validation with Landsat-derived quantities}

The camera-derived velocities are averaged over \pm 3 days and binned to be equivalent to the relatively sparse Landsatderived quantities. Landsat-derived velocities indicate velocity differences less than $1.2 \mathrm{md}^{-1}$, or $8 \%$, compared with camera-derived velocities (Fig. 6). Landsat-derived velocities are relatively sparse in time, having variable time separation, i.e. 9-30 days.

\subsection{Validation with camera pairs}

Two cameras were placed at the Umiamako and Store sites (Table 2). The Umiamako (Store) cameras are separated by $2.9 \mathrm{~km}(1.7 \mathrm{~km})$. The ' $\mathrm{B}$ ' sites are further up-glacier. The average velocities from these two perspectives are equivalent on average between the sites, i.e. within the budgeted error (Table 8). However, the velocity variations from these differing perspectives do not have equivalent correlations: Umiamako $R^{2}=0.77$ and Store $R^{2}=0.64$. We attribute the differing correlations to the different perspective and flow direction with respect to the cameras. The perspective difference strongly influences illumination. The time series of running correlation indicates a fluctuation with many values having correlation greater than 0.9 and periods of correlation dropping out.

\section{GLACIOLOGICAL RESULTS}

Figure 6 illustrates the much higher temporal frequency of camera-derived velocities than is available from multi-day satellite image pairs. The time interval in sequential

Table 8. West Greenland glacier velocity statistics from time-lapse photogrammetry

\begin{tabular}{|c|c|c|c|c|c|c|c|}
\hline \multirow[t]{2}{*}{ Site } & $\begin{array}{c}\text { Uncertainty } \\
\text { average }\end{array}$ & Average & Std dev. & $\begin{array}{l}\text { Uncertainty/ } \\
\text { Velocity }\end{array}$ & Min. & Max. & Range \\
\hline & $\mathrm{md}^{-1}$ & $\mathrm{md}^{-1}$ & $\mathrm{md}^{-1}$ & $\%$ & $\mathrm{md}^{-1}$ & $\mathrm{md}^{-1}$ & $\%$ \\
\hline Rink Isbræ & 0.5 & 14.1 & 0.7 & 3.5 & 13.0 & 15.5 & 17.3 \\
\hline Store Gletscher A & 0.3 & 13.7 & 0.7 & 2.2 & 11.1 & 15.3 & 31.1 \\
\hline Store Gletscher B & 0.3 & 13.7 & 0.7 & 2.2 & 11.1 & 15.0 & 28.5 \\
\hline Umiamako A & 0.5 & 5.7 & 0.5 & 8.8 & 4.8 & 6.8 & 34.7 \\
\hline Umiamako B & 0.4 & 6.0 & 0.6 & 6.7 & 5.2 & 7.4 & 37.3 \\
\hline Jakobshavn Isbræ & 0.8 & 39.7 & 3.9 & 2.0 & 32.4 & 47.6 & 38.4 \\
\hline
\end{tabular}


camera-derived pairs is 1-4 days, translating to effective 12 hour temporal resolution (section 3.5). Daily observation frequency reveals coherent multi-day velocity trends and relatively abrupt changes. The vertical solid lines in Figure 6 indicate major calving events identified by visual inspection in sequential hourly time-lapse images. At Rink Isbræ on 19 August and 12 September 2007, the calving of 'ice islands' $>1 \mathrm{~km}$ in length led to $\sim 10$ day progressive accelerations of $18 \%$ and $15 \%$ (Fig. $6 a$ and b), respectively. A 22 June 2007 calving event at Umiamako led to a progressive $\sim 6$ day $17 \%$ acceleration (Fig. 6c). Jakobshavn Isbræ, on 3 and 26 July 2007, exhibited acceleration of $6 \%$ and $7 \%$, respectively, over 7 days after calving (Fig. $6 \mathrm{~d}$ and e). These accelerations need to be analyzed in terms of the area of calving, the event location with respect to the medial flowline, the glacier front shape, the abruptness of the calving given that some events last days before complete detachment, the existence of sea ice, whether the tongue is grounded or floating, glacier thickness changes, etc.

The $17-38 \%$ velocity range during the mid-June to lateSeptember period considered in this study (Table 8) is larger than has previously been reported. In this section, we discuss this finding in the context of sub-annual variability on a glacier-by-glacier basis.

\subsection{Jakobshavn Isbræ}

Seasonality in flow speed for Jakobshavn Isbræ appears to have emerged with the 1999-2003 progressive disintegration of its ice shelf. Between 1985 and 1986, Echelmeyer and Harrison (1990) found no measurable seasonally averaged speed variation. For 2004-07, Joughin and others (2008) attributed a maximum of $15 \%$ of speed fluctuations, at a point roughly $4 \mathrm{~km}$ from the terminus, to terminusposition changes, with maximum speed occurring when the front had retreated most. Our daily observations in 2007 indicate a gradual acceleration of $38 \%$ as the perennial ice shelf and glacier terminus disintegrated to a new retreated minimum. Amundson and others (2010) found that a multi$\mathrm{km}$ long ice melange packed in the fjord slows the calving rate and regulates seasonal advances of the ice front, and therefore its speed and ice discharge.

\subsection{Umiamako}

According to Howat and others (2010), in 1999 the Umiamako terminus position exhibited seasonal oscillations of a few hundred meters, advancing in the spring and then retreating with the clearing of the calved glacier ice and landfast sea-ice melange. Using approximately weekly Landsat imagery, in 2001 they observed a $~ 50 \%$ speed increase, from $1.2 \mathrm{~m} \mathrm{~d}^{-1}$ in April to $2.5 \mathrm{~m} \mathrm{~d}^{-1}$ in mid-June, followed by a return to $1.3 \mathrm{~m} \mathrm{~d}^{-1}$ flow through mid-September. In 2003, Umiamako began a progressive $4 \mathrm{~km}$ retreat lasting at least until 2009. Ice-flow speed increased from a melt-season peak of $2.3 \mathrm{~m} \mathrm{~d}^{-1}$ before 2003 , to $6.5 \mathrm{~m} \mathrm{~d}^{-1}$ in 2009 , roughly a factor of three increase. We observe velocities consistent with the Umiamako post-2003 retreat acceleration, i.e. $4.8-7.4 \mathrm{~m} \mathrm{~d}^{-1}$ (Fig. 6; Table 8). In terms of seasonality, we compute a $\sim 36 \%$ range in June-September daily speeds. Thus, like Jakobshavn Isbræ, Umiamako has gained seasonality and speed during a period of retreat. We thus confirm that velocity variations seem strongly controlled by flow resistance imposed by glacier and sea-ice jamming at the front.

\subsection{Store Gletscher}

Similar to Jakobshavn and Umiamako, an acceleration $(\sim 30 \%)$ is evident at Store Gletscher from the earliest observations of the year when an ice melange imposed flow resistance at the front (Fig. 6). Our observations ended before an end-of-melt deceleration could be confirmed.

\subsection{Rink Isbræ}

The ice-discharge rate of Rink Isbræ has been estimated to be roughly equivalent to that of Store Gletscher (Weidick and Bennike, 2007). We find a $3 \%$ higher mean flow velocity and a $17 \%$ higher minimum speed for Rink Isbræ than for Store Gletscher. Rink Isbræ calves larger bergs, some wider $(>1 \mathrm{~km})$ than they are deep $(\sim 0.6 \mathrm{~km})$, such that they do not immediately turn over. Rink Isbræ exhibits the most distinct multi-day speed variations among our sites (Fig. 6). We speculate that unlike Store Gletscher, Rink Isbræ calves ice islands because it is nearer flotation.

\section{CONCLUSIONS}

Daily time-lapse camera images can be used to precisely quantify glacier motion in image space, i.e. with pixels $\mathrm{d}^{-1}$ units. By projecting the camera view geometry onto a digital terrain model, it is possible to assign horizontal scale to converting displacements into velocities $\left(\mathrm{m} \mathrm{d}^{-1}\right)$. The ASTER image geolocation and elevation uncertainty results in angular uncertainty of $\pm 0.3^{\circ}$, corresponding to planimetric $\pm 30 \mathrm{~m}$ errors at $3 \mathrm{~km}$ distance. Comparison between terrestrial photogrammetric velocities and velocities derived from $15 \mathrm{~m}$ Landsat 7 imagery confirms the feasibility of retrieving velocities in orthometric coordinates.

Before pixel displacements and ice velocities are calculated, a series of procedures are applied, including manual image filtering of images confounded by weather (e.g. by fog or rain droplets on the camera enclosure window). Fortunately, fog is uncommon in fjords continually flushed by relatively warm and dry katabatic winds. Hardware failures have resulted in data gaps of $>1$ week, especially in the first year of operation before including a more robust timer. Camera motion is compensated using matching of motionless features on land on the near and far sides of the glacier that flows through the middle of the image. In the case of Jakobshavn Isbræ, with no motionless land features in the upper part of the image, a less robust 'affine transformation' approach is used to compensate camera motion, producing uncertainties roughly twice as large as the glacier situations with land in the foreground and farground. Fortunately, Jakobshavn Isbræ has the highest velocity in our survey (maximum $47.6 \mathrm{~m} \mathrm{~d}^{-1}$, average $37.6 \mathrm{~m} \mathrm{~d}^{-1}$ ), resulting in the lowest speed uncertainty $\left(2 \%\right.$, or $\left.3.9 \mathrm{~m} \mathrm{~d}^{-1}\right)$ among the sites. The slowest glacier in our survey, Umiamako, flowing $5.9 \mathrm{~m} \mathrm{~d}^{-1}$ on average, has an associated mean speed uncertainty of $9 \%$, or $0.5 \mathrm{~m} \mathrm{~d}^{-1}$.

Image enhancement includes principal-component intensity and $90^{\circ}$ and $0^{\circ}$ edge-detection filters. The use of multiple image enhancements and multiple image chip sizes in matching procedures produces distinctly better matching performance than matching single image pairs. Intensity image pairs produce $25 \%$ higher matching correlation values than red, green or blue greyscale image pairs. $90^{\circ}$ and $0^{\circ}$ edge and high-pass filtered image pairs contribute 
only a few percent to the displacement retrievals. The directional or high-pass filtered images seem to outperform the principal-component images only in hazy cases. A clustering technique, not possible with only one displacement vector, as in conventional matching, facilitates rejection of high-correlation false matches.

The red image 'band' outperforms the other (green and blue) bands at the Umiamako site. The blue band performs best (highest correlation) at Rink and Store glaciers. A more comprehensive study of performance by bands may yield conclusive image-band-based matching improvements.

At distances of $\sim 3 \mathrm{~km}$ and given the range of observed displacements, the uncertainty in matching becomes as large as the computed displacements, rendering the technique applicable to an area limited to the lowest few $\mathrm{km}$ of the glacier, the fastest areas of the glacier, or the areas nearest the camera. Higher camera placements are possible but are confounded by increased cloudiness and are harder to reach on foot.

Resolvable displacement is a function of (1) pixel footprint derived from target distance, (2) ice velocity and (3) time-lapse interval. For relatively slow glaciers, a longer time interval or closer features have a similar effect. In the case of Rink Isbræ, which has 14-18 pixels $\mathrm{d}^{-1}$ displacements, with a calculated absolute uncertainty of 0.52 pixels, the displacement uncertainty is $20 \%$. The resolvable lapsing interval becomes $\sim 4.5$ hours. Halving the distance halves the minimum interval of resolvable displacement to 2.5 hours. A relatively slow glacier, flowing $2 \mathrm{~m} \mathrm{~d}^{-1}$, having 3.2-pixel displacement at a distance of $1000 \mathrm{~m}$, with $0.62 \mathrm{~m}$ pixel size, requires a $>1$ day time interval for a displacement to exceed the uncertainty.

The minimum resolvable displacement is a function of camera focal length, pixel size on the ground, distance to target, ice velocity, and registration precision. A first necessary condition for motion to be resolved is that the displacement exceeds the registration and matching uncertainty, here 0.3 pixels. In our case, the registration error is roughly twice as large as the matching error. Thus, the success of this approach depends most on compensating camera motions that result from wind, the settling of the ground, interference by wild animals, human visitors, etc.

A preliminary analysis of daily velocities suggests that major calving events are responsible for the largest day-today velocity changes, which are progressive accelerations requiring up to 10 days for maximum speed to be reached. After the calving-induced acceleration, the velocity gradually declines, presumably as resistance to flow rebuilds. A greater seasonality is evident, not just given the ability to observe more frequently than the at-best weekly satellite perspective, but as the fronts of marine-terminating glaciers retreat.

Terrestrial photogrammetry opens new possibilities for investigating the sensitivity of glacier dynamics to climate variability. Daily displacements retrieved from time-lapse camera images yield higher spatial/temporal resolution near the calving front than is typical of conventional remote-sensing techniques. Continuous GPS or autotheodolite reflectors can provide higher temporal resolution, yet provide more complex Lagrangian point measurements, while the time-lapse imaging technique can yield Eulerian data with broader coverage, especially at the hazardous calving front where the survivability of in situ sensors is limited.

\section{ACKNOWLEDGEMENTS}

Major support for this research was provided by NASA grant NNX06AE31G managed by Ming-Ying Wei and The Ohio State University's Climate, Water and Carbon (CWC) program managed by D. Alsdorf. This work has benefited from camera system development by J. Balog, W.T. Pfeffer and A. Lewinter. A. Behar and N. Humphrey provided electrical engineering assistance. Guidance from $\mathrm{H}$. Brecher, D. Merchant and A. Schenk provided an important conceptual foundation for this work. We thank J. Orlowski and O.J. Hammeken for assistance with fieldwork. Major logistical support was provided by J. Buenning, M. Begnauld, S. Zager and R. Abbott of CH2MHillPolar Field Services, and E. Vaughn of the US Air National Guard. I. Howat helped obtain Landsat and ASTER imagery and contributed constructive ideas and discussions on the MIMC approach. Constructive comments from T. James and an anonymous reviewer improved the clarity of the manuscript. We thank Nikon and The North Face for EIS sponsorship. This is Byrd Polar Research Center contribution No. 1397.

\section{REFERENCES}

Abdalati, W. and 9 others. 2001. Outlet glacier and margin elevation changes: near-coastal thinning of the Greenland ice sheet. J. Geophys. Res., 106(D24), 33,729-33,742.

Ahn, Y. and I.M. Howat. 2009. Automated glacier surface velocity using Multi-Image/Multi-Chip (MIMC) feature tracking. [Abstr. C23C-0510.] Eos, 90(52), Fall Meet. Suppl.

Amundson, J.M., M. Truffer, M.P. Lüthi, M. Fahnestock, M. West and R.J. Motyka. 2008. Glacier, fjord, and seismic response to recent large calving events, Jakobshavn Isbræ, Greenland. Geophys. Res. Lett., 35(22), L22501. (10.1029/2008GL035281.)

Amundson, J.M., M. Fahnestock, M. Truffer, J. Brown, M.P. Lüthi and R.J. Motyka. 2010. Ice mélange dynamics and implications for terminus stability, Jakobshavn Isbræ, Greenland. J. Geophys. Res., 115(F1), F01005. (10.1029/2009JF001405.)

Bauer, A. 1968. Missions aériennes de reconnaissance au Groenland 1957-1958. Medd. Grønl., 173(3).

Brecher, H.H. and L.G. Thompson. 1993. Measurement of the retreat of Qori Kalis glacier in the tropical Andes of Peru by terrestrial photogrammetry. Photogramm. Eng. Remote Sens., 59(6), 1017-1022.

Brown, L.G. 1992. A survey of image registration techniques. ACM Comput. Surv., 24(4), 325-376.

Carbonnell, M. and A. Bauer. 1968. Exploitation des couvertures photographiques aériennes répétées du front des glaciers vêlant dans Disko Bugt et Umanak Fjord, juin-juillet, 1964. Medd. Grønl., 173(5)

Chapuis, A., C. Rolstad and R. Norland. 2010. Interpretation of amplitude data from a ground-based radar in combination with terrestrial photogrammetry and visual observations for calving monitoring of Kronebreen, Svalbard. Ann. Glaciol., 51(55), 34-40.

Csatho, B., T. Schenk, C.J. van der Veen and W.B. Krabill. 2008. Intermittent thinning of Jakobshavn Isbræ, West Greenland, since the Little Ice Age. J. Glaciol., 53(184), 131-144.

Dietrich, R. and 6 others. 2007. Jakobshavn Isbræ, West Greenland: flow velocities and tidal interaction of the front area from 2004 field observations. J. Geophys. Res., 112(F3), F03S21. (10.1029/ 2006JF000601.)

Echelmeyer, K. and W.D. Harrison. 1990. Jakobshavns Isbræ, West Greenland: seasonal variations in velocity - or lack thereof. J. Glaciol., 36(122), 82-88.

Evans, A.N. 2000. Glacier surface motion computation from digital image sequences. IEEE Trans. Geosci. Remote Sens., 38(2), 1064-1072. 
Fastook, J.L., H.H. Brecher and T.J. Hughes. 1995. Derived bedrock elevations, strain rates and stresses from measured surface elevations and velocities: Jakobshavns Isbræ, Greenland. J. Glaciol., 41(137), 161-173.

Fischler, M.A. and R.C. Bolles. 1981. Random sample consensus: a paradigm for model fitting with applications to image analysis and automated cartography. Commun. ACM, 24(6), 381-395.

Fountain, A.G. 1983. Columbia Glacier photogrammetric altitude and velocity: data set (1975-1981). USGS Open File Rep. 82-756.

Gonzales, R.C. and R.E. Woods. 2002. Digital image processing. Second edition. Upper Saddle River, NJ, Prentice Hall.

Hamilton, G.S. and I.M. Whillans. 2000. Point measurements of mass balance of the Greenland ice sheet using precision vertical global positioning system (GPS) surveys. J. Geophys. Res., 105(B7), 16,295-16,301.

Harper, J.T., N.F. Humphrey, W.T. Pfeffer and B. Lazar. 2007. Two modes of accelerated glacier sliding related to water. Geophys. Res. Lett., 34(12), L12503. (10.1029/2007GL030233.)

Harrison, W.D., K.A. Echelmeyer, D.M. Cosgrove and C.F. Raymond. 1992. The determination of glacier speed by time-lapse photography under unfavourable conditions. J. Glaciol., 38(129), 257-265.

Howat, I.M., I.R. Joughin and T.A. Scambos. 2007. Rapid changes in ice discharge from Greenland outlet glaciers. Science, 315(5818), 1559-1561.

Howat, I.M., J.E. Box, Y. Ahn, A. Herrington and E. McFadden. 2010. Seasonal variability in the dynamics of marine-terminating outlet glaciers in Greenland. J. Glaciol., 56(198), 601-613.

Joughin, I., W. Abdalati and M.A. Fahnestock. 2004. Large fluctuations in speed on Greenland's Jakobshavn Isbræ glacier. Nature, 432(7017), 608-610.

Joughin, I., S.B. Das, M.A. King, B.E. Smith, I.M. Howat and T. Moon. 2008. Seasonal speedup along the western flank of the Greenland Ice Sheet. Science, 320(5877), 781-783.

Krabill, W.B. and 9 others. 2000. Greenland ice sheet: highelevation balance and peripheral thinning. Science, 289(5478), 428-430.

Luckman, A., T. Murray, R. de Lange and E. Hanna. 2006. Rapid and synchronous ice-dynamic changes in East Greenland. Geophys. Res. Lett., 33(3), L03503. (10.1029/2005GL025428.)

Maas, H.-G., R. Dietrich, E. Schwalbe, M. Bässler and P. Westfeld. 2006. Analysis of the motion behaviour of Jakobshavn Isbræ
Glacier in Greenland by monocular image sequence analysis. Int. Arch. Photogramm. Remote Sens., 16(5), 179-183.

Motyka, R.J., L. Hunter, K.A. Echelmeyer and C. Connor. 2003. Submarine melting at the terminus of a temperate tidewater glacier, LeConte Glacier, Alaska, U.S.A. Ann. Glaciol., 36, 57-65.

Motyka, R., M. Fahnestock, I.M. Howat, M. Truffer, H. Brecher and M. Luethi. 2008. Jakobshavn Isbrae, Greenland: DEMs, orthophotos, surface velocities, and ice loss derived from photogrammetric re-analysis of July 1985 repeat aerial photography. [Abstr. C13A-0563.] Eos, 89(52), Fall Meet. Suppl.

O'Neel, S., K.A. Echelmeyer and R.J. Motyka. 2003. Short-term variations in calving of a tidewater glacier: LeConte Glacier, Alaska, U.S.A. J. Glaciol., 49(167), 587-598.

Rignot, E. and P. Kanagaratnam. 2006. Changes in the velocity structure of the Greenland Ice Sheet. Science, 311(5673), 986-990.

Scambos, T.A., M.J. Dutkiewicz, J.C. Wilson and R.A. Bindschadler. 1992. Application of image cross-correlation to the measurement of glacier velocity using satellite image data. Remote Sens. Environ., 42(3), 177-186.

Schenk, T. 1999. Digital photogrammetry. Laurelville, $\mathrm{OH}$, TerraScience.

Schwalbe, E., H.-G. Maas, R. Dietrich and H. Ewert. 2008. Glacier velocity determination from multi-temporal long range laser scanner point clouds. Int. Arch. Photogramm. Remote Sens., 37(B5), 457-462.

Skvarca, P., B. Raup and H. De Angelis. 2003. Recent behaviour of Glaciar Upsala, a fast-flowing calving glacier in Lago Argentino, southern Patagonia. Ann. Glaciol., 36, 184-188.

Slama, C.C., C. Theurer and S.W. Henriksen, eds. 1980. Manual of photogrammetry. Fourth edition. Falls Church, VA, American Society of Photogrammetry.

Sohn, H.G., K.C. Jezek and C.J. van der Veen. 1998. Jakobshavn Glacier, West Greenland: 30 years of spaceborne observations. Geophys. Res. Lett., 25(14), 2699-2702.

Weidick, A. and O. Bennike. 2007. Quaternary glaciation history and glaciology of Jakobshavn Isbræ and the Disko Bugt region: a review. Copenhagen, Geological Survey of Denmark and Greenland. (GEUS Bulletin 14.)

Zitová, B. and J. Flusser. 2003. Image registration methods: a survey. Image Vision Comput., 21(11), 977-1000.

MS received 21 August 2009 and accepted in revised form 5 June 2010 